\title{
ARTICLE
}

\section{Substrate-water exchange in photosystem II is arrested before dioxygen formation}

Håkan Nilsson ${ }^{1}$, Fabrice Rappaport ${ }^{2}$, Alain Boussac ${ }^{3}$ \& Johannes Messinger ${ }^{1}$

Light-driven oxidation of water into dioxygen, catalysed by the oxygen-evolving complex (OEC) in photosystem II, is essential for life on Earth and provides the blueprint for devices for producing fuel from sunlight. Although the structure of the OEC is known at atomic level for its dark-stable state, the mechanism by which water is oxidized remains unsettled. Important mechanistic information was gained in the past two decades by mass spectrometric studies of the $\mathrm{H}_{2}{ }^{18} \mathrm{O} / \mathrm{H}_{2}{ }^{16} \mathrm{O}$ substrate-water exchange in the four (semi) stable redox states of the OEC. However, until now such data were not attainable in the transient states formed immediately before the $\mathrm{O}-\mathrm{O}$ bond formation. Using modified photosystem II complexes displaying up to 40 -fold slower $\mathrm{O}_{2}$ production rates, we show here that in the transient $\mathrm{S}_{3} \mathrm{Y}_{Z}$ state the substrate-water exchange is dramatically slowed as compared with the earlier $\mathrm{S}$ states. This further constrains the possible sites for substrate-water binding in photosystem II.

\footnotetext{
${ }^{1}$ Department of Chemistry, Kemiskt Biologiskt Centrum (KBC), Umeå University, Linnaeus väg 6, 90187 Umeå, Sweden. ${ }^{2}$ Institut de Biologie PhysicoChimique, UMR 7141 CNRS and Université Pierre et Marie Curie, 13 rue Pierre et Marie Curie, 75005 Paris, France. ${ }^{3}$ iBiTec-S, CNRS UMR 8221 , CEA Saclay, 91191 Gif-sur-Yvette, France. Correspondence and requests for materials should be addressed to A.B. (email: alain.boussac@cea.fr) or to J.M. (email: johannes.messinger@chem.umu.se).
} 
P hotosynthesis provides the driving force for most life on Earth by converting sunlight into chemical energy. Cyanobacteria, algae and higher plants couple two photosystems in series to exploit water as the electron and proton source for the synthesis of carbohydrates from $\mathrm{CO}_{2}$. In the process they replenish the atmosphere with the dioxygen we live on. The complex four-electron four-proton chemistry of water oxidation is catalysed in photosystem II (PSII) by an inorganic cluster containing the earth-abundant metals $\mathrm{Mn}$ and $\mathrm{Ca}$, which are bridged by five oxygen ${ }^{1-9}$. The structure of this $\mathrm{Mn}_{4} \mathrm{CaO}_{5}$ cluster, which together with its ligands forms the oxygen-evolving complex (OEC), is now known at the atomic scale in its darkstable state ${ }^{4}$. Density functional theory-based refinements have provided OEC structures (Fig. 1a) that can rationalize the vast majority of the available spectroscopic data ${ }^{6-8,10-14}$.

Water oxidation to dioxygen is energetically driven by lightinduced charge separations within the reaction centre of PSII. These occur between the chlorophyll-containing photo-oxidant $\mathrm{P} 680 / \mathrm{P}_{680^{\circ}+}$ and the primary electron acceptor pheophytin. The OEC and P680 are connected via the redox-active tyrosine residue 161 of the $\mathrm{D} 1$ protein $\left(\mathrm{Y}_{\mathrm{Z}} / \mathrm{Y}_{\mathrm{Z}}^{\bullet}\right)$ (Fig. 1a). In this way the OEC steps in response to short light flashes almost in synchrony through the four (semi)-stable oxidation states $\mathrm{S}_{0} \mathrm{Y}_{\mathrm{Z}}, \mathrm{S}_{1} \mathrm{Y}_{\mathrm{Z}}, \mathrm{S}_{2}^{+} \mathrm{Y}_{\mathrm{Z}}$ and $\mathrm{S}_{3}^{+} \mathrm{Y}_{\mathrm{Z}}$ (Fig. 1b), where the subscript signifies the number of stored oxidizing equivalents, and the plus sign indicates an extra charge caused by the lack of proton release during the transition from the dark-stable $S_{1} Y_{Z}$ state to the $S_{2}^{+} Y_{Z}$ state. These (semi)stable intermediates of water oxidation can be trapped with high yield and are thereby readily accessible for biophysical investigation. Although it is largely agreed that the S-state transitions between $\mathrm{S}_{0} \mathrm{Y}_{\mathrm{Z}}$ and $\mathrm{S}_{3}^{+} \mathrm{Y}_{\mathrm{Z}}$ involve $\mathrm{Mn}$-centred oxidation of the $\mathrm{Mn}_{4} \mathrm{CaO}_{5}$ cluster ${ }^{6,9,15}$, some experimental results suggest ligand (oxo-bridge) participation and/or a structural change during the $\mathrm{S}_{2}{ }^{+} \mathrm{Y}_{\mathrm{Z}} \Rightarrow \mathrm{S}_{3}^{+} \mathrm{Y}_{\mathrm{Z}}$ transition ${ }^{16-18}$. The dark-stable $\mathrm{S}_{1} \mathrm{Y}_{\mathrm{Z}}$ state is generally considered to have the formal oxidation states $\mathrm{Mn}_{4}$ (III,III,IV,IV) (high oxidation state scenario) ${ }^{6,15,19}$, but also the lower valent $\mathrm{Mn}_{4}(\mathrm{II}, \mathrm{III}, \mathrm{III}, \mathrm{IV}) / \mathrm{Mn}_{4}(\mathrm{III}, \mathrm{III}, \mathrm{III}, \mathrm{III})$ options are discussed $^{20,21}$.

Water oxidation starts only after the fourth oxidizing equivalent has been accumulated in the OEC, that is, once the transient $\mathrm{S}_{3}^{+} \mathrm{Y}_{\mathrm{Z}}^{\bullet}$ state is reached (Fig. 1c). It is widely agreed that this dioxygen-forming reaction sequence starts with a proton release during the $\mathrm{S}_{3}^{+} \mathrm{Y}_{\mathrm{Z}}^{\bullet} \rightarrow \mathrm{S}_{3} \mathrm{Y}_{\mathrm{Z}}^{\circ}$ transition ${ }^{22-25}$, followed by the formation of a $\mathrm{Ca}$ - or $\mathrm{Mn}$-bound oxyl radical or of a $\mathrm{Mn}^{\mathrm{V}}$-oxo group due to oxidation of the cluster by $\mathrm{Y}_{\mathrm{Z}}^{\bullet 6,14,26}$. Although the following reaction steps towards $\mathrm{O}_{2}$ must include the formation of a bound peroxidic intermediate, dioxygen formation and release, and the rebinding of substrate water ${ }^{27,28}$ (Fig. 1c), the exact nature of the chemistry involved remains unsettled, as these transient states have so far largely eluded biophysical investigations $6,14,28-32$. O-O formation by nucleophilic attack may occur, for example, either between a free (Fig. 2a) $)^{29}$ or a Ca-bound (Fig. 2b) ${ }^{32-35}$ substrate water (the term 'substrate water' is used throughout the manuscript irrespective of the protonation state of the substrate oxygen) and a $\mathrm{Mn}^{\mathrm{V}}=\mathrm{O}$ or $\mathrm{Mn}^{\mathrm{IV}}$-oxyl radical. Alternatively, the $\mathrm{O}-\mathrm{O}$ bond may be formed via radical coupling between either a Ca-oxyl radical and an $\mathrm{Mn}$ bound oxyl radical (Fig. 2c) ${ }^{14}$, or between an Mn-oxyl radical and an Mn-oxo (bridge) (Fig. 2d) 6,30,31,36.

Substrate-water exchange experiments, which monitor the rate of incorporation of isotopically labelled bulk water into the substrate sites of the OEC, have allowed determining the relative binding characteristics of the two substrate-water molecules in all (meta)-stable $\mathrm{S}_{\mathrm{i}} \mathrm{Y}_{\mathrm{Z}}$ states under various conditions, and have a

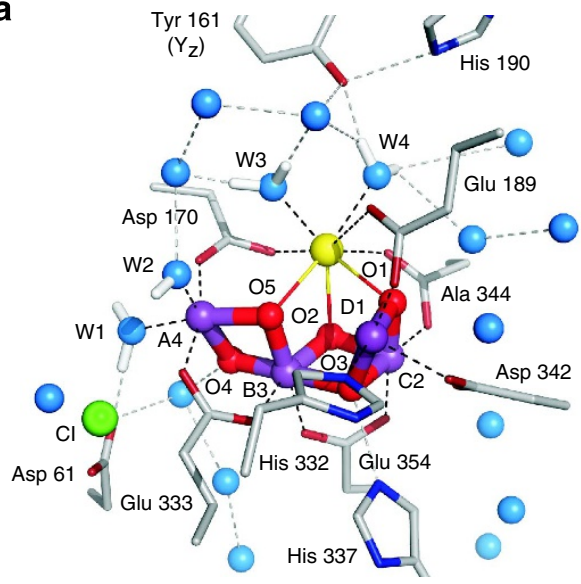

b

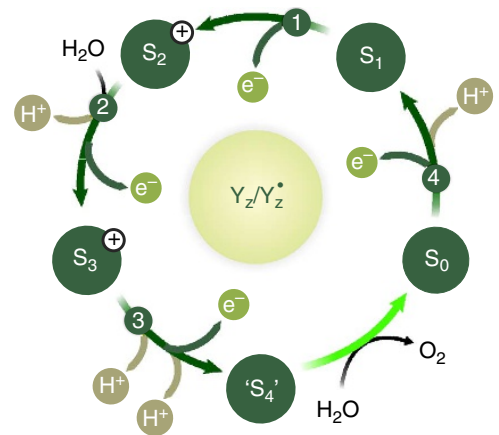

C

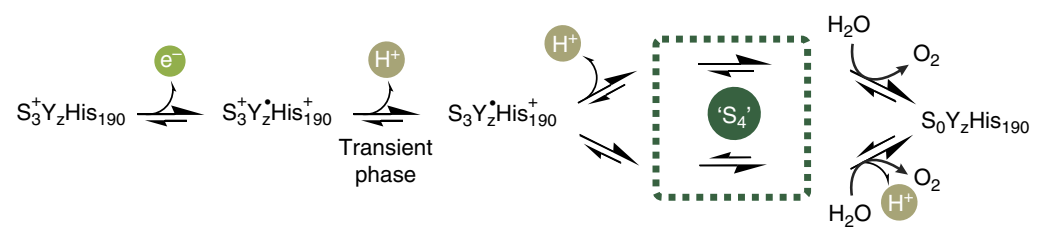

Figure 1 | The water-oxidizing complex in PSII and its reaction sequence. (a) Density functional theory-based model of the $\mathrm{Mn}_{4} \mathrm{CaO}_{5} \mathrm{cluster}$ in the 'open cube' $\left(\mathrm{S}_{2}\right.$ EPR multiline) configuration together with its water derived ligands W1-W $4^{12}$. The model is inserted into the 1.9- $\AA$ crystal structure of photosystem II ${ }^{4}$. Mn ${ }^{I I I / I V}$, purple; $\mathrm{Ca}^{2+}$, yellow; oxo-bridges, red; water-oxygens, blue; $\mathrm{Cl}^{-}$, green; amino acid backbones, grey; carboxy-oxygen, red; and His-nitrogen, dark blue. (b) Kok cycle for water oxidation in PSII including proton release to the bulk ${ }^{8,22}$ (see also Supplementary Note 1) and water-binding events ${ }^{27,28}$. The $S_{i}$ states $(i=0, \ldots, 4)$ denote the oxidation state of the $\mathrm{Mn}_{4} \mathrm{CaO}_{5}$ cluster relative to the $S_{0}$ state, while the plus sign indicates a positive extra charge. (c) Detailed sequence of known and postulated states during molecular oxygen formation. Protons released in sequence $\mathbf{c}$ may in part be taken up by internal bases created in earlier $S_{i}$ state transitions ${ }^{29}$. 
thereby provided unique insight into the mechanism of photosynthetic water oxidation ${ }^{28-31,37-40}$. In these experiments, PSII samples are preset to the desired $\mathrm{S}_{\mathrm{i}} \mathrm{Y}_{\mathrm{Z}}$ state by light flashes, and are then rapidly mixed with $\mathrm{H}_{2}{ }^{18} \mathrm{O}$. After desired incubation times they are further advanced by flashes to produce dioxygen. The isotopic composition of the product $\mathrm{O}_{2}\left({ }^{16,16} \mathrm{O}_{2},{ }^{16,18} \mathrm{O}_{2}\right.$, ${ }^{18,18} \mathrm{O}_{2}$ ) is monitored by membrane-inlet mass spectrometry ${ }^{41}$, and the substrate-water exchange rates are calculated from the $\mathrm{H}_{2}{ }^{18} \mathrm{O}$ incubation time dependence of the $\mathrm{m} / \mathrm{z} 34$ and $\mathrm{m} / \mathrm{z} 36$ signals $^{26,42}$. Assessing whether the two substrate waters can still exchange with the bulk water just before $\mathrm{O}-\mathrm{O}$ bond formation, that is, in the transient $\mathrm{S}_{3}^{+} \mathrm{Y}_{\mathrm{Z}}^{\circ}$ and $\mathrm{S}_{3} \mathrm{Y}_{\mathrm{Z}}^{*}$ states, is expected to provide additional information on the nature and the binding sites of the two substrate waters, and therefore on the chemistry of water oxidation.

Thus far, only very few time-resolved studies were able to probe these two transient states $22,24,25,43,44$ and no information about substrate-water binding in the $\mathrm{S}_{3}^{+} \mathrm{Y}_{\mathrm{Z}}^{\bullet}$ and $\mathrm{S}_{3} \mathrm{Y}_{\mathrm{Z}}^{\bullet}$ states is available as yet. This is mainly because the halftimes of these states in native PSII samples are too short $(\leq 1-2 \mathrm{~ms})$ with respect to the mixing dead time in the water-exchange experiments $\left(t_{1 / 2}=3 \mathrm{~ms}\right.$; see Supplementary Fig. 1). Recent a

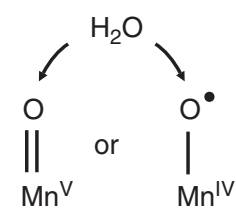

C<smiles>COCCON</smiles>

b

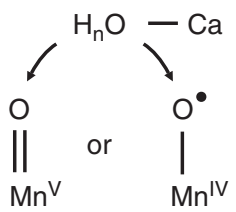

d<smiles>COCO[V]([NH3+])([O-])Cl</smiles>

Figure 2 | Conceivable $\mathbf{O}-\mathbf{O}$ bond formation mechanisms in the ' $\mathbf{S}_{\mathbf{4}}$ ' state of PSII. (a) Nucleophilic attack by a bulk water onto a $\mathrm{Mn}^{\mathrm{V}}=\mathrm{O}$ or $\mathrm{Mn}^{\mathrm{IV}}$ oxyl radical ${ }^{29}$, (b) nucleophilic attack by a Ca bound water onto a $\mathrm{Mn} \vee=0$ or $\mathrm{Mn}^{\mathrm{IV}}$-oxyl radical ${ }^{26,32-35}$, (c) coupling of a Ca-hydroxyl radical with a Mn-bound radical substrate ${ }^{14}$, (d) direct coupling between a terminal $\mathrm{Mn}$-oxyl radical with an oxo bridge between $\mathrm{Ca}$ and $\mathrm{Mn}^{6,28,30,31,36}$. studies set conditions though whereby the lifetimes of these transient states can be extended while preserving the overall function of the enzyme ${ }^{45,46}$. It was found that Thermosynechococcus elongatus cells growing on $\mathrm{Sr}^{2+}$. containing media devoid of $\mathrm{Ca}^{2+}$ incorporate $\mathrm{Sr}^{2+}$ in place of $\mathrm{Ca}^{2+}$ into the OEC and that $\mathrm{Cl}^{-}$can be exchanged biochemically against $\mathrm{Br}^{-}$or $\mathrm{I}^{-}$(Fig. 1a); importantly, these substitutions have only minor structural effects ${ }^{9,47-50}$, but extend the half-lifetime of the $\mathrm{S}_{3} \mathrm{Y}_{\mathrm{Z}}^{\bullet}$ state to $7 \mathrm{~ms}$ ( $\mathrm{Sr} / \mathrm{Br}$-PSII) or even $45 \mathrm{~ms} \quad(\mathrm{Sr} / \mathrm{I}-\mathrm{PSII})^{45,46}$. These samples thereby provide the opportunity to probe the rates of substrate-water exchange in this last transient before $\mathrm{O}_{2}$ formation (Fig. 1c).

Here we show that the exchange of both substrate waters is strongly retarded in the transient $\mathrm{S}_{3} \mathrm{Y}_{Z}^{\bullet}$ state as compared with the semi-stable $\mathrm{S}_{3}{ }^{+} \mathrm{Y}_{\mathrm{Z}}$ state. Four possible mechanisms for this simultaneous retardation of the exchange of both substrate waters induced by $\mathrm{Y}_{\mathrm{Z}}$ oxidation and the subsequent deprotonation of the catalytic site are presented and evaluated. On the basis of this evaluation and present literature data we conclude that W2 is most likely to be the fast exchanging substrate water $\left(\mathrm{W}_{\mathrm{f}}\right)$, while O5 (or W3) can be assigned to be the slowly exchanging substrate water $\left(\mathrm{W}_{\mathrm{s}}\right)$.

\section{Results}

Substrate-water exchange in the $\mathrm{S}_{3}^{+} \mathbf{Y}_{\mathrm{Z}}$ state. Substrate-water exchange measurements were performed for the $S_{3}^{+} Y_{Z}$ state to determine the influence of co-factor substitution on the substrate-water binding affinity in PSII core samples of T. elongatus. For this, the dark-adapted PSII samples were excited with two saturating flashes to advance the PSII complexes from the dark-stable $\mathrm{S}_{1} \mathrm{Y}_{\mathrm{Z}}$ state into the semi-stable $\mathrm{S}_{3}{ }^{+} \mathrm{Y}_{\mathrm{Z}}$ state. $\mathrm{H}_{2}{ }^{18} \mathrm{O}$ was then injected at defined times before inducing dioxygen formation by giving one additional flash to the enzyme ${ }^{26,28,37}$.

Figures 3a,b compare the substrate-water exchange kinetics in the $\mathrm{S}_{3}^{+} \mathrm{Y}_{\mathrm{Z}}$ state of native $\mathrm{Ca} / \mathrm{Cl}$ samples of $T$. elongatus with samples in which these cofactors were replaced by either $\mathrm{Sr} / \mathrm{Br}$ or $\mathrm{Sr} / \mathrm{I}$. The native $\mathrm{Ca} / \mathrm{Cl}$-PSII shows the typical biphasic kinetics for the rise of the mixed labelled ${ }^{16,18} \mathrm{O}_{2}$ (Fig. 3a), and the corresponding monophasic rise for the doubly labelled ${ }^{18,18} \mathrm{O}_{2}$ species (Fig. 3b). As described previously, the fast ${ }^{16,18} \mathrm{O}_{2}$ rise reflects the exchange of the fast exchanging substrate water $\left(\mathrm{W}_{\mathrm{f}}\right)$, while the subsequent slow increase of the ${ }^{16,18} \mathrm{O}_{2}$ signal and the a

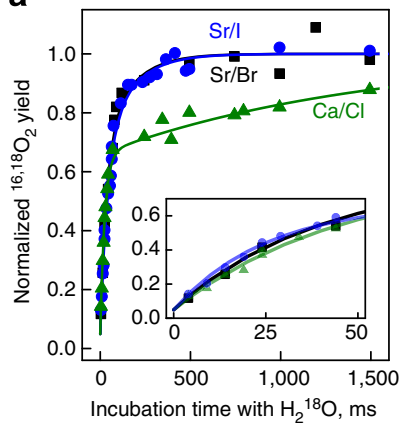

b

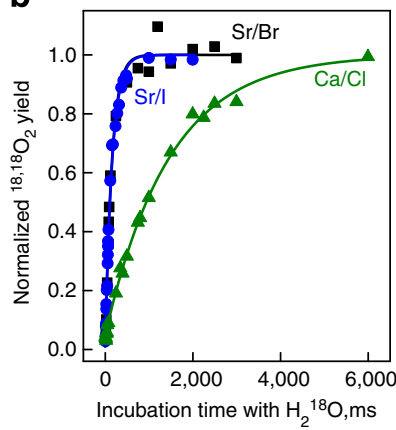

C

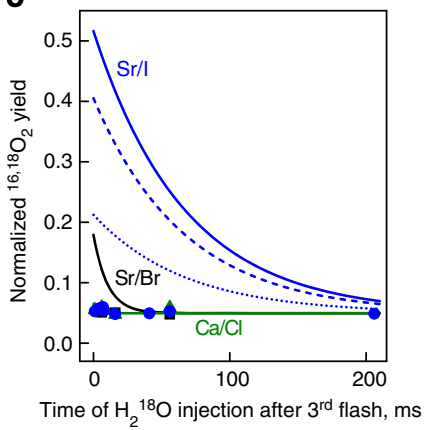

Figure 3 | Substrate-water exchange in T. elongatus PSII core particles containing different ionic cofactors. (a,b) The substrate water exchange in the $\mathrm{S}_{3}^{+} \mathrm{Y}_{\mathrm{Z}}$ state at $\mathrm{m} / \mathrm{z} 34\left({ }^{16,18} \mathrm{O}_{2} ; \mathbf{a}\right)$ and $\mathrm{m} / \mathrm{z} 36\left({ }^{18,18} \mathrm{O}_{2} ; \mathbf{b}\right)$, while $\mathbf{c}$ displays the exchange in the $\mathrm{S}_{3} \mathrm{Y}_{\mathbf{Z}}$ state at $\mathrm{m} / \mathrm{z}=34$. Symbols mark the data points (green triangles, $\mathrm{Ca} / \mathrm{Cl}-\mathrm{PSII}$; black squares, $\mathrm{Sr} / \mathrm{Br}$-PSII; blue circles, $\mathrm{Sr} / \mathrm{I}-\mathrm{PSII}$ ), while full lines are fits representing the fast and slow substrate-water exchange ( $\mathbf{a}, \mathbf{b}$; for rate constants see Table 1) or simulations of the expected experimental outcome assuming the exchange rates are identical in the $\mathrm{S}_{3}^{+} \mathrm{Y}_{Z}$ and $\mathrm{S}_{3} \mathrm{Y}_{Z}$ states (c). The blue dashed and dotted lines in $\mathbf{c}$ represent simulations where either the slow (dashed) or fast (dotted) rate of exchange was set to be 1,000 times slower than that measured in the $\mathrm{S}_{3}^{+} Y_{Z}$ state (Table 1). All data points $(n=1)$ are normalized to values reached after complete isotopic equilibration. Each time course was measured once, but consists of many separately measured data points that were in part obtained on different days. 


\begin{tabular}{|c|c|c|c|}
\hline & $\mathrm{Ca} / \mathrm{Cl}-\mathrm{PSII}$ & Sr/Br-PSII & Sr/I-PSII \\
\hline \multicolumn{4}{|c|}{$\overline{\mathrm{S}_{3}^{+} \mathrm{Y}_{\mathrm{Z}}^{\boldsymbol{\theta}} \rightarrow \mathrm{S}_{3} \mathrm{Y}_{\mathrm{Z}}^{\boldsymbol{\theta}} \rightarrow \mathrm{S}_{0} \mathrm{Y}_{\mathrm{Z}}}$} \\
\hline $\begin{array}{l}k_{1}, s^{-1} \\
k_{2}, s^{-1}\end{array}$ & $\begin{array}{c}6030 \pm 60 \\
630 \pm 6\end{array}$ & $\begin{array}{c}3010 \pm 30 \\
96 \pm 9\end{array}$ & $\begin{array}{l}>700 \\
15 \pm 3\end{array}$ \\
\hline \multicolumn{4}{|c|}{ Water exchange, $\mathrm{S}_{3}^{+} \mathrm{Y}_{\mathrm{Z}}$} \\
\hline $\begin{array}{l}k_{f,} s^{-1} \\
k_{S}, s^{-1}\end{array}$ & $\begin{array}{c}40 \pm 4 \\
0.69 \pm 0.06\end{array}$ & $\begin{array}{l}29 \pm 3 \\
6.6 \pm 0.5\end{array}$ & $\begin{array}{l}25 \pm 3 \\
6.3 \pm 0.3\end{array}$ \\
\hline
\end{tabular}

The water exchange (this study) and transient optical measurements (data from refs 45,46 ) were performed at $20^{\circ} \mathrm{C}$ and $\mathrm{pH} 6.5$ with T. elongatus photosystem II (PSII) core particles containing the indicated cofactors.

rise of the double-labelled ${ }^{18,18} \mathrm{O}_{2}$ species (Fig. 3b) reflect the exchange of the slowly exchanging substrate water $\left(\mathrm{W}_{\mathrm{s}}\right)^{26}$.

The biological substitution of $\mathrm{Ca}^{2+}$ by $\mathrm{Sr}^{2+}$ leads to a tenfold acceleration of the slow exchange without significantly affecting $\mathrm{W}_{\mathrm{f}}$ (Fig. 3a,b and Table 1). This is in good agreement with an earlier higher plant study, in which biochemical replacement of $\mathrm{Ca}^{2+}$ by $\mathrm{Sr}^{2+}$ was found to cause a fourfold acceleration of $\mathrm{W}_{\mathrm{s}}$ exchange $\mathrm{e}^{51}$. This specific effect on the slow substrate-water exchange is useful, as it allows the detection of the exchange of both substrate waters in the $\mathrm{S}_{3} \mathrm{Y}_{\mathrm{Z}}^{\bullet}$ state (see below). Finally, the substitution of $\mathrm{Br}^{-}$for $\mathrm{I}^{-}$has only a modest effect on the water exchange in the $\mathrm{S}_{3}^{+} \mathrm{Y}_{\mathrm{Z}}$ state as evidenced by the similar exchange characteristics obtained with the $\mathrm{Sr} / \mathrm{Br}$ - and Sr/I-PSII samples (Fig. 3a,b).

Substrate-water exchange in the $S_{3} Y_{Z}^{\bullet}$ state. On the basis of the exchange rates determined for the semi-stable $\mathrm{S}_{3}^{+} \mathrm{Y}_{\mathrm{Z}}$ state, substrate water-exchange experiments in the transient $\mathrm{S}_{3} \mathrm{Y}_{\mathrm{Z}}^{\bullet}$ state (Fig. 3c) were performed for all three sample types $(\mathrm{Ca} / \mathrm{Cl}, \mathrm{Sr} / \mathrm{Br}$, $\mathrm{Sr} / \mathrm{I})$. In these experiments, the dark-adapted PSII samples were advanced from the $S_{1} Y_{Z}$ state by three saturating flashes into the transient $\mathrm{S}_{3}^{+} \mathrm{Y}_{Z}^{\bullet}$ state to initiate the $\mathrm{O}_{2}$-forming reaction sequence (Fig. 1c). After this third flash, $\mathrm{H}_{2}{ }^{18} \mathrm{O}$ was injected at various delay times, and the ${ }^{18} \mathrm{O}$ incorporation into the product $\mathrm{O}_{2}$ was monitored. The symbols in Fig. $3 \mathrm{c}$ show that no incorporation of the ${ }^{18} \mathrm{O}$-label occurred for any of the three sample types, not even in the relatively long-lived $\mathrm{S}_{3} \mathrm{Y}_{\mathrm{Z}}^{\bullet}$ state of the Sr/I-PSII samples. This shows that the bulk $\mathrm{H}_{2}{ }^{18} \mathrm{O}$ exchanges too slowly with the already bound ${ }^{16} \mathrm{O}$-substrate to allow incorporation of the ${ }^{18} \mathrm{O}$-label into the $\mathrm{O}_{2}$ product.

The extent to which the substrate-water exchange is slowed in the $\mathrm{S}_{3} \mathrm{Y}_{\mathrm{Z}}^{\bullet}$ state versus $\mathrm{S}_{3}^{+} \mathrm{Y}_{\mathrm{Z}}$ is illustrated by the computed exchange curves in Fig. 3c. The longer lifetimes of both the $\mathrm{S}_{3}^{+} \mathrm{Y}_{Z}^{\bullet}$ and $\mathrm{S}_{3} \mathrm{Y}_{\mathrm{Z}}^{\bullet}$ states should have resulted in relative ${ }^{16,18} \mathrm{O}_{2}$ signals of $51( \pm 6) \%$ and $18( \pm 2) \%$ in the Sr/I-PSII and Sr/Br-PSII samples, respectively, if the exchange rates were the same as in the $S_{3}^{+} Y_{Z}$ state. Such yields are well above the detection limit, which allows the detection of ${ }^{16,18} \mathrm{O}_{2}$ formation even at natural abundance (Fig. 3c and Supplementary Fig. 2). Interestingly, the dashed and dotted blue curves show that a 1,000-fold slowing of only one of the exchange rates, while keeping the other one unchanged, cannot explain the data. Thus, our results imply that the exchange rates of both substrate waters are significantly retarded during the $\mathrm{S}_{3}^{+} \mathrm{Y}_{\mathrm{Z}} \Rightarrow \mathrm{S}_{3}^{+} \mathrm{Y}_{\mathrm{Z}}^{\bullet} \rightarrow \mathrm{S}_{3} \mathrm{Y}_{\mathrm{Z}}^{\bullet}+\mathrm{H}^{+}$transitions. These simulations demonstrate that the corresponding other substrate water exchange rate needs to be additionally slowed by a factor $>30$ for $W_{f}$ (if $W_{s}$ is slowed by a factor of 1,000 ) and $>10$ for $W_{s}$ (if $W_{\mathrm{f}}$ is slowed by a factor of 1,000 ), to make them consistent with the data.
As a consequence, the exchange rate of $\mathrm{W}_{\mathrm{f}}$ in the $\mathrm{S}_{3} \mathrm{Y}_{\mathrm{Z}}^{\bullet}$ state is $<0.83 \mathrm{~s}^{-1}$, and is thus at least tenfold slower than the exchange rate of $\mathrm{W}_{\mathrm{s}}$ in the $\mathrm{S}_{3}^{+} \mathrm{Y}_{\mathrm{Z}}$ state of the $\mathrm{Sr} / \mathrm{I}$ samples, and at least as slow as the exchange of $\mathrm{W}_{\mathrm{s}}$ in the Ca/Cl-PSII. It is emphasized that neither the overall oxygen production yield nor the period four oscillations were markedly affected by the cofactor substitutions $^{45,46}$ (see also Supplementary Fig. 3), showing that this observation is made with enzyme that despite the slowed final $\mathrm{O}_{2}$-producing transition functions normally.

\section{Discussion}

In catalysis, either in biology or in chemistry, isotope labelling studies are instrumental for elucidating reaction mechanisms ${ }^{52}$. In such experiments the substrate is labelled with a (stable) isotope and the propagation of this label into intermediates and/or the product(s) is followed. When studying the mechanism of water oxidation, $\mathrm{H}_{2}{ }^{18} \mathrm{O}$ is typically added to a reactive species that has been pre-formed in unlabelled water. As an example, this method provided the demonstration that in a synthetic Mn-oxo complex, $\mathrm{O}_{2}$ is produced by nucleophilic attack of hydroxide on $\mathrm{Mn}{ }^{\mathrm{V}} \equiv \mathrm{O}$ (ref. 53). The characteristic signature for this mechanism is the evolution of ${ }^{16,18} \mathrm{O}_{2}$ at a ratio equal to the ${ }^{18} \mathrm{O}$-enrichment of bulk water. In contrast, we did not observe here any incorporation of ${ }^{18} \mathrm{O}$ into the dioxygen product above the natural abundance level, when injecting $\mathrm{H}_{2}{ }^{18} \mathrm{O}$ into PSII suspensions poised in the $\mathrm{S}_{3} \mathrm{Y}_{Z}^{\circ}$ state, even when the lifetime of the $\mathrm{S}_{3} \mathrm{Y}_{\mathrm{Z}}^{\bullet}$ state was significantly lengthened by the exchange of $\mathrm{Ca}^{2+}$ by $\mathrm{Sr}^{2}+$ and $\mathrm{Cl}^{-}$by $\mathrm{I}^{-}$(Fig. 3c). It is noted that the $\mathrm{S}_{3} \mathrm{Y}_{\mathrm{Z}}^{\bullet}$ state of PSII is comparable to $\mathrm{Mn} V$ in the above model complex in the sense that the O-O bond is formed without the acquisition of any additional oxidizing equivalents. In absence of an unprecedented diffusion barrier ${ }^{54,55}$, which would need to arise during the $\mathrm{S}_{3}^{+} \mathrm{Y}_{\mathrm{Z}} \Rightarrow \mathrm{S}_{3}^{+} \mathrm{Y}_{\mathrm{Z}}^{\bullet} \rightarrow$ $\mathrm{S}_{3} \mathrm{Y}_{\mathrm{Z}}^{\bullet}+\mathrm{H}^{+}$transitions, the observed lack of ${ }^{16,18} \mathrm{O}_{2}$ formation directly excludes that in PSII the O-O bond is formed in the same way as in the $\mathrm{Mn}^{\mathrm{V}} \equiv \mathrm{O}$ model system ${ }^{53}$. In other terms, the nucleophilic attack of free water onto an electrophilic oxygen species (Fig. 2a) does not occur in PSII. This conclusion is consistent with previous data that showed that both substrate waters are bound to the OEC already in the $S_{2}$ and $S_{3}$ states ${ }^{56,57}$. However, nucleophilic attack of a Ca-bound water/hydroxo onto a $\mathrm{Mn}^{\mathrm{V}} \equiv \mathrm{O} / \mathrm{Mn}^{\mathrm{V}}=\mathrm{O} / \mathrm{Mn}^{\mathrm{IV}}-\mathrm{O}^{\bullet}$ group (Fig. $\left.2 \mathrm{~b}\right)^{26,32-35}$ or coupling of a Ca-bound oxyl radical with a high valent Mn-oxo group (Fig. 2c) ${ }^{14}$ may take place, if conditions are present in PSII that slow down the exchange of the Ca-bound substrate water seven to eight orders of magnitude over the exchange rates reported for water ligated to $\mathrm{Ca}^{2}+$ in aqueous solutions ${ }^{37,39,40,58}$. Alternatively, both substrate -waters may be $\mathrm{Mn}$-ligated and form the $\mathrm{O}-\mathrm{O}$

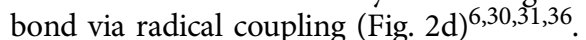

The lack of ${ }^{16,18} \mathrm{O}_{2}$ and ${ }^{18,18} \mathrm{O}_{2}$ production (Fig. 3c) demonstrates that the exchange of both substrate waters is significantly slower than the decay of the $\mathrm{S}_{3} \mathrm{Y}_{\mathrm{Z}}^{\bullet}$ state into $\mathrm{S}_{0} \mathrm{Y}_{\mathrm{Z}}+\mathrm{O}_{2}$, even when the $\mathrm{O}_{2}$ production is severely slowed by cofactor exchange. The fact that the exchange of both substrate waters is slowed down so significantly despite a constant redox state of the $\mathrm{Mn}_{4} \mathrm{CaO}_{5}$ cluster is important, and we discuss below the four possible mechanisms for 'arresting' both substrate waters under these conditions.

The simplest possibility (mechanism 1) for slowing down significantly the exchange of both substrate waters would be the existence of the $\mathrm{O}-\mathrm{O}$ bond (peroxide) already in the $\mathrm{S}_{3} \mathrm{Y}_{\mathrm{Z}}^{\bullet}$ state ${ }^{59,60}$. At this point, the ${ }^{18} \mathrm{O}$-label from the injected water could not be incorporated into the product and thus no ${ }^{16,18} \mathrm{O}_{2}$ would be observed. Although internally consistent, this hypothesis is at odds with a recent time resolved X-ray spectroscopy experiment, which excluded $\mathrm{Mn}$ reduction 
(formation of the formal $\mathrm{S}_{1}\left(\mathrm{O}_{2}\right)^{2-} \mathrm{Y}_{\mathrm{Z}}^{\bullet}$ intermediate) during the transient phase (Fig. 1c). This implies that the $\mathrm{O}-\mathrm{O}$ bond is formed at a later stage of the reaction cycle ${ }^{8,43}$, and rules out peroxide formation in the $\mathrm{S}_{3} \mathrm{Y}_{\mathrm{Z}}^{\bullet}$ state as an explanation for the arrested water change.

An alternative interpretation (mechanism 2) is that the oxidation state of $\mathrm{Y}_{\mathrm{Z}}$ strongly influences the substrate-water exchange via the $\mathrm{H}$-bonding network around the $\mathrm{Mn}_{4} \mathrm{CaO}_{5}$ cluster, which includes the two water ligands of $\mathrm{Ca}$ (W3 and W4; Fig. 1a). The oxidation of $Y_{Z}$ (that is, $Y_{Z}^{\circ}$ formation) is coupled to the transfer of its phenolic proton to the nearby D1-His190 (Fig. 1a) ${ }^{61,62}$. This proton movement undoubtedly changes the $\mathrm{H}$-bonding network ${ }^{4,63,64}$ around the $\mathrm{Y}_{\mathrm{Z}} / \mathrm{Ca}$ site and, as a consequence, may affect the exchange of the two substrate waters. This line of thought is partially supported by earlier data obtained with the alkaline-induced $\mathrm{S}_{2}{ }^{\prime} \mathrm{Y}_{\mathrm{Z}}^{\bullet}$ state (the dash denotes a likely difference in protonation state and/or water ligation with respect to the $\mathrm{S}_{2}^{+} \mathrm{Y}_{\mathrm{Z}}$ state), which was generated by addition of base to the preformed $\mathrm{S}_{3}^{+} \mathrm{Y}_{\mathrm{Z}}$ state ${ }^{65}$. These studies demonstrated that the substrate-water exchange is 5- to 20 -fold slower in the $\mathrm{S}_{2}{ }^{\prime} \mathrm{Y}_{\mathrm{Z}}{ }_{\mathrm{Z}}$ state than in the $\mathrm{S}_{2}^{+} \mathrm{Y}_{\mathrm{Z}}$ state ${ }^{42,65}$. The magnitude of this change is, however, too small to account for the 1000-fold decrease needed for at least one of the two substrates to explain the lack of ${ }^{18} \mathrm{O}$ labelling of the dioxygen observed here (Fig. 3c). Nevertheless, this option cannot be completely ruled out, and, if true, would be a remarkable demonstration of the interconnectivity of all components of the OEC.

A third option (mechanism 3) correlates the arrest of the substrate-water exchange with the deprotonation event on the $\mathrm{Mn}_{4} \mathrm{CaO}_{5}\left(\mathrm{H}_{\mathrm{n}} \mathrm{O}\right)_{4}$ cluster that was previously reported to occur during the $\mathrm{S}_{3}^{+} \mathrm{Y}_{\mathrm{Z}}^{\bullet} \rightarrow \mathrm{S}_{3} \mathrm{Y}_{\mathrm{Z}}^{\bullet}+\mathrm{H}^{+}$transition (Fig. 1c) ${ }^{22}$ and is demonstrated here to also occur in the $\mathrm{Sr} / \mathrm{Br}$-PSII samples (Supplementary Figs 4-10, Supplementary Note 1 and Supplementary Methods). This proton release could explain a 1,000 -fold decrease of one of the substrate-water exchange rates, if $\mathrm{W}_{\mathrm{f}}$ or $\mathrm{W}_{\mathrm{s}}$ is deprotonated. Notably, this could also account for a simultaneous slowing of the other substrate water (that is, at least 10- to 30-fold; see above), if the exchanges of both substrate waters are coupled (see ref. 28), or if the exchange of the other substrate is simultaneously slowed by mechanism 2 .

Finally (mechanism 4), a recent theoretical study concluded that substrate-water exchange can only occur in PSII, if at least one $\mathrm{Mn}$ ion within the $\mathrm{Mn}_{4} \mathrm{CaO}_{5}$ cluster is in the $\mathrm{Mn}^{\mathrm{III}}$ redox state ${ }^{40}$. Thus, to exchange a water ligand in the $\mathrm{S}_{3}^{+} \mathrm{Y}_{\mathrm{Z}}$ state, the $\mathrm{Mn}_{4} \mathrm{CaO}_{5}$ cluster must first be transiently reduced by $\mathrm{Y}_{\mathrm{Z}}$ to generate the exchange-competent $S_{2}^{\prime \prime} Y_{Z}^{\bullet}$ state (which may differ from the $S_{2}^{+} Y_{Z}$ and $S_{2}{ }^{\prime} Y_{Z}^{*}$ states discussed above in its protonation state and/or water binding). This requires the $\mathrm{S}_{2}^{\prime \prime} \mathrm{Y}_{Z}^{\circ}$ state and $\mathrm{S}_{3}^{+} \mathrm{Y}_{\mathrm{Z}}$ state to be almost isoenergetic with low transition barrier, allowing for a fast redox equilibrium with an appreciable probability to form the $S_{2}^{\prime \prime} Y_{Z}^{*}$ state. If this is the mechanism for substrate exchange in the $\mathrm{S}_{3}^{+} \mathrm{Y}_{\mathrm{Z}}$ state, then the substrate-water exchange in the $\mathrm{S}_{3} \mathrm{Y}_{\mathrm{Z}}^{\bullet}$ state would indeed be expected to be impeded, simply because in this state the $\mathrm{Mn}_{4} \mathrm{CaO}_{5}$ cluster cannot be transiently re-reduced by the oxidized $\mathrm{Y}_{\mathrm{Z}}^{\circ}$. As such, our data provide the first experimental support to this theoretical prediction. We note, however, that mechanism 4 critically depends on the condition that both substrate waters are ligated to $\mathrm{Mn}$ and that all $\mathrm{Mn}$ ions in the $\mathrm{S}_{3}^{+} \mathrm{Y}_{\mathrm{Z}}$ and $\mathrm{S}_{3} \mathrm{Y}_{\mathrm{Z}}^{\bullet}$ states are in the oxidation state $\mathrm{Mn}^{\mathrm{IV}}$, while the alternative explanations (mechanisms 2 and 3) do not.

Experiments and theoretical calculations conducted by several groups have suggested that W2, W3, O5 (Fig. 1a) or WX (a water that is proposed to bind to the $\mathrm{Mn}_{4} \mathrm{CaO}_{5}$ cluster during the $\mathrm{S}_{2}^{+} \mathrm{Y}_{\mathrm{Z}} \Rightarrow \mathrm{S}_{3}^{+} \mathrm{Y}_{\mathrm{Z}}$ transition) are likely candidates for the two substrate waters $4,6,28,39,40,66,67$. In a very recent work, WX was ruled out as the immediate substrate by clearly demonstrating that both substrates are already bound in the $\mathrm{S}_{2}^{+} \mathrm{Y}_{Z}$ state $^{57}$. Our present substrate-water exchange experiments in the $\mathrm{S}_{3}^{+} \mathrm{Y}_{\mathrm{Z}}$ state (Fig. 3a,b and Table 1) show that the exchange of $\mathrm{W}_{\mathrm{f}}$ is only marginally affected by biological $\mathrm{Ca} / \mathrm{Sr}$ substitution, while the exchange of $\mathrm{W}_{\mathrm{s}}$ occurs ten times faster in the Sr-PSII sample. The fact that the difference between $\mathrm{W}_{\mathrm{f}}$ and $\mathrm{W}_{\mathrm{s}}$ is even stronger after biological substitution than after chemical exchange ${ }^{51}$ considerably strengthens the previous suggestion ${ }^{30,51}$ that $\mathrm{W}_{\mathrm{f}}$ is not a ligand of $\mathrm{Ca}^{2+}$. This point is further supported by the data presented here on water exchange in the $\mathrm{S}_{3} \mathrm{Y}_{\mathrm{Z}}^{\circ}$ state, which show that the exchange rate of $\mathrm{W}_{\mathrm{f}}$ is at least commensurate with the exchange rate of $\mathrm{W}_{\mathrm{s}}$ in the $\mathrm{S}_{3}{ }^{+} \mathrm{Y}_{\mathrm{Z}}$ state. Thus, from the short list above, $\mathrm{W} 2$ appears to be the most probable candidate for $\mathrm{W}_{\mathrm{f}}{ }^{39,57}$. In contrast, the tenfold dependence of the binding affinity of $\mathrm{W}_{\mathrm{s}}$ on biosynthetic $\mathrm{Ca} / \mathrm{Sr}$ substitution reported here provides additional strong support for a direct bond between $\mathrm{Ca} / \mathrm{Sr}$ and $\mathrm{W}_{s}^{51}$. This makes W3 (ref. 39) and O5 the most likely candidates for $\mathrm{W}_{\mathrm{s}}$ with $\mathrm{O} 5$ being favoured, owing to the $\mathrm{S}_{\mathrm{i}} \mathrm{Y}_{\mathrm{Z}}$ state dependence of the $W_{s}$ exchange rate $e^{28,30,58,67}$ even though a definitive assignment will require additional experimental support.

For the first time, the exchangeability of the substrate-water molecules has been probed in the last transient state before the $\mathrm{O}-\mathrm{O}$ bond formation. This provides important additional constraints for the ongoing identification of the substrate-water binding sites at the $\mathrm{Mn}_{4} \mathrm{CaO}_{5}$ cluster and for the elucidation of the mechanism of water oxidation in PSII. The discovery that both substrate waters are non-exchangable in the last transient state before $\mathrm{O}_{2}$ formation suggests that arresting the exchange of both substrate water molecules, rather than just one, is a mechanistic requirement. We propose, in line with the finding that the slowing down of oxygen evolution on $\mathrm{Ca} / \mathrm{Sr}$ substitution stems from a change in entropy ${ }^{68}$, that this lack of exchange with the bulk water reflects a highly ordered arrangement of the OEC that is essential for low-energy $\mathrm{O}-\mathrm{O}$ bond formation.

\section{Methods}

Preparation of the PSII samples. The T. elongatus strain used was the $\Delta$ psbA1 $\Delta$ psbA2 deletion mutant ${ }^{69}$ constructed from the $T$. elongatus $43-\mathrm{H}$ strain that had a His6-tag on the carboxy terminus of CP43 (ref. 70). The biological $\mathrm{Ca} / \mathrm{Sr}$ and the biochemical $\mathrm{Cl} / \mathrm{Br}$ exchanges were achieved as previously described ${ }^{45,46,68}$ $\mathrm{Ca} / \mathrm{Cl}$-PSIIs, Sr/Cl-PSIIs and Sr/Br-PSIIs were purified with the protocol already described ${ }^{68}$. For the $\mathrm{Cl}^{-} / \mathrm{I}^{-}$exchange ${ }^{46}, \mathrm{Sr} / \mathrm{Cl}$-PSII's bound to the Ni column were washed overnight with $\sim 8-10$ column volumes of a buffer containing $10 \%$ glycerol, $1 \mathrm{M}$ betaine, $100 \mathrm{mM} \mathrm{NaCl}, 15 \mathrm{mM} \mathrm{CaCl}, 15 \mathrm{mM}, \mathrm{MgCl}_{2}, 40 \mathrm{mM}$ MES, $1 \mathrm{mM}$ L-histidine, $0.03 \% \beta$-dodecyl maltoside, $\mathrm{pH} 6.5$ ( $\mathrm{pH}$ adjusted with $\mathrm{NaOH}$ ). Next, the PSII core complexes bound to the resin were washed with one volume equivalent of a buffer containing $10 \%$ glycerol, $1 \mathrm{M}$ betaine, $1 \mathrm{mM} \mathrm{NaI}$, $15 \mathrm{mM} \mathrm{Ca}(\mathrm{OH})_{2}, 15 \mathrm{mM} \mathrm{Mg}(\mathrm{OH})_{2}, 1 \mathrm{mM}$ L-histidine, $0.03 \% \beta$-dodecyl maltoside MES $40 \mathrm{mM}$, pH 6.5 (adjusted by addition of $\mathrm{NaOH}$ ). The PSII's were then eluted with a buffer containing, $1 \mathrm{M}$ betaine, $1 \mathrm{mM} \mathrm{NaI}, 15 \mathrm{mM} \mathrm{Ca}(\mathrm{OH})_{2}, 15 \mathrm{mM}$ $\mathrm{Mg}(\mathrm{OH})_{2}, 200 \mathrm{mM}$ L-histidine, $0.03 \% \beta$-dodecyl maltoside, $\mathrm{pH} 6.5$ (adjusted by addition of MES powder). The eluted PSII samples were then washed by using Amincon-ultra-15 $100 \mathrm{~K}$ concentrators in a buffer containing $1 \mathrm{M}$ betaine, $1 \mathrm{mM} \mathrm{NaI}, 15 \mathrm{mM} \mathrm{Ca}(\mathrm{OH})_{2}, 15 \mathrm{mM} \mathrm{Mg}(\mathrm{OH})_{2}, 40 \mathrm{mM}$ MES $40 \mathrm{mM}$, pH 6.5 ( $\mathrm{pH}$ adjusted with $\mathrm{NaOH}$ ). PSII samples were frozen at $77 \mathrm{~K}$ in liquid nitrogen until use.

Substrate-water exchange measurements. An isotope ratio mass spectrometer (ThermoFinnigan Delta plus XP) connected to a membrane-inlet cuvette $(165 \mu \mathrm{l})$ via a cooling trap (liquid $\mathrm{N}_{2}$ ) was used to measure substrate-water exchange at $20^{\circ} \mathrm{C}^{26,28,41}$. The substrate-water exchange in the $\mathrm{S}_{3}^{+} \mathrm{Y}_{\mathrm{Z}}$ state was studied by illuminating PSII, highly enriched in the $\mathrm{S}_{1} \mathrm{Y}_{\mathrm{D}}^{\circ}$ state by a preflash and subsequent dark-adaptation, with two saturating Xe-flashes $(2 \mathrm{~Hz})$, followed by $\mathrm{H}_{2}{ }^{18} \mathrm{O}$ injection at various times before the third flash, which was given at a fixed time after the second flash ( $6 \mathrm{~s}$ for Ca/Cl-PSII, $3 \mathrm{~s}$ for Sr/Br-PSII, $2 \mathrm{~s}$ for Sr/I-PSII). Four flashes $(2 \mathrm{~Hz})$ were given $5 \mathrm{~min}$ after the third turnover flash for normalization purpose. For the $\mathrm{S}_{3} \mathrm{Y}_{\mathrm{Z}}^{\bullet}$ state measurements the $\mathrm{S}_{1} \mathrm{Y}_{\mathrm{D}^{-}}^{\bullet}$-enriched PSII samples were illuminated with three flashes $(2 \mathrm{~Hz})$ followed by $\mathrm{H}_{2}{ }^{18} \mathrm{O}$ injection at various times after the third flash, and the normalizing flash sequence. The $\mathrm{S}_{3}^{+} \mathrm{Y}_{\mathrm{Z}}$ data were treated and fit within an Excel spread sheet employing equations ${ }^{34} \mathrm{Y}=0.66\left(1-\exp \left(-{ }^{34} k_{\mathrm{f}} \cdot \mathrm{t}\right)\right)+0.34\left(1-\exp \left(-{ }^{34} k_{s} \cdot \mathrm{t}\right)\right)$ and ${ }^{36} \mathrm{Y}=1-\exp \left(-{ }^{36} k \cdot \mathrm{t}\right)$, 
where ${ }^{34} \mathrm{Y}$ and ${ }^{36} \mathrm{Y}$ signify the incubation time dependent ${ }^{16,18} \mathrm{O}_{2}$ and ${ }^{18,18} \mathrm{O}_{2}$ yields, respectively ${ }^{26,42}$. The expected ${ }^{16,18} \mathrm{O}_{2}$ yields for the $\mathrm{S}_{3} \mathrm{Y}_{\mathrm{Z}}^{*}$ state experiments were calculated in $1 \mathrm{~ms}$ intervals and then summed up over the whole decay $(3,000 \mathrm{~ms})$ within Excel by folding the monoexponetial $\mathrm{S}_{3} \mathrm{Y}_{\mathrm{Z}}^{\bullet}$ decay with the increasing $\mathrm{H}_{2}{ }^{18} \mathrm{O}$ enrichment in the two binding sites. By varying the delay time between $\mathrm{S}_{3} \mathrm{Y}_{2}^{\circ}$ formation (third flash) and start of $\mathrm{H}_{2}{ }^{18} \mathrm{O}$ enrichment (injection), the expected ${ }^{16,18} \mathrm{O}_{2}$ yield was calculated for delays up to $210 \mathrm{~ms}$. Injection artefacts, Chl dilution and $\mathrm{H}_{2}{ }^{18} \mathrm{O}$ mixing were accounted for as in the $\mathrm{S}_{3}^{+} \mathrm{Y}_{\mathrm{Z}}$ experiments.

\section{References}

1. Ferreira, K. N., Iverson, T. M., Maghlaoui, K., Barber, J. \& Iwata, S. Architecture of the photosynthetic oxygen-evolving center. Science 303, 1831-1838 (2004).

2. Yano, J. et al. Where water is oxidized to dioxygen: structure of the photosynthetic $\mathrm{Mn}_{4} \mathrm{Ca}$ cluster. Science 314, 821-825 (2006).

3. Guskov, A. et al. Cyanobacterial photosystem II at $2.9 \AA$ resolution and the role of quinones, lipids, channels and chloride. Nat. Struct. Biol. Mol. Biol. 16, 334-342 (2009).

4. Umena, Y., Kawakami, K., Shen, J. R. \& Kamiya, N. Crystal structure of oxygenevolving photosystem II at a resolution of 1.9 Å. Nature 473, 55-61 (2011).

5. Tsui, E. Y. \& Agapie, T. Reduction potentials of heterometallic manganeseoxido cubane complexes modulated by redox-inactive metals. Proc. Natl Acad. Sci. USA 110, 10084-10088 (2013).

6. Siegbahn, P. E. M. Water oxidation mechanism in photosystem II, including oxidations, proton release pathways, $\mathrm{O}-\mathrm{O}$ bond formation and $\mathrm{O}_{2}$ release. Biochim. Biophys. Acta 1827, 1003-1019 (2013).

7. Ames, W. et al. Theoretical evaluation of structural models of the $S_{2}$ state in the oxygen evolving complex of photosystem II: protonation states and magnetic interactions. J. Am. Chem. Soc. 133, 19743-19757 (2011).

8. Dau, H., Zaharieva, I. \& Haumann, M. Recent developments in research on water oxidation by photosystem II. Curr. Opin. Chem. Biol. 16, 3-10 (2012).

9. Cox, N., Pantazis, D. A., Neese, F. \& Lubitz, W. Biological water oxidation. Acc. Chem. Res. 46, 1588-1596 (2013).

10. Luber, $\mathrm{S}$. et al. $\mathrm{S}_{1}$-state model of the $\mathrm{O}_{2}$-evolving complex of photosystem II. Biochemistry 50, 6308-6311 (2011).

11. Schinzel, S., Schraut, J., Arbuznikov, A. V., Siegbahn, P. E. M. \& Kaupp, M. Density functional calculations of ${ }^{55} \mathrm{Mn},{ }^{14} \mathrm{~N}$ and ${ }^{13} \mathrm{C}$ electron paramagnetic resonance parameters support an energetically feasible model system for the $\mathrm{S}_{2}$ state of the oxygen-evolving complex of photosystem II. Chem. Eur. J. 16, 10424-10438 (2010).

12. Pantazis, D. A., Ames, W., Cox, N., Lubitz, W. \& Neese, F. Two interconvertible structures that explain the spectroscopic properties of the oxygen-evolving complex of photosystem II in the $\mathrm{S}_{2}$ state. Angew. Chem. Int. Ed. 51, 9935-9940 (2012).

13. Gatt, P., Petrie, S., Stranger, R. \& Pace, R. J. Rationalizing the $1.9 \AA$ crystal structure of photosystem II-a remarkable Jahn-Teller balancing act induced by a single proton transfer. Angew. Chem. Int. Ed. 51, 12025-12028 (2012).

14. Isobe, H. et al. Theoretical illumination of water-inserted structures of the $\mathrm{CaMn}_{4} \mathrm{O}_{5}$ cluster in the $\mathrm{S}_{2}$ and $\mathrm{S}_{3}$ states of oxygen-evolving complex of photosystem II: full geometry optimizations by B3LYP hybrid density functional. Dalt. Trans. 41, 13727-13740 (2012).

15. Dau, H. \& Haumann, M. The manganese complex of photosystem II in its reaction cycle-Basic framework and possible realization at the atomic level. Coord. Chem. Rev. 252, 273-295 (2008).

16. Glatzel, P. et al. Electronic structural changes of $\mathrm{Mn}$ in the oxygen-evolving complex of photosystem II during the catalytic cycle. Inorg. Chem. 52, 5642-5644 (2013)

17. Glöckner, C. et al. Structural changes of the oxygen-evolving complex in photosystem II during the catalytic cycle. J. Biol. Chem. 288, 22607-22620 (2013).

18. Messinger, J. et al. Absence of $\mathrm{Mn}$ centered oxidation in the $\mathrm{S}_{2}$ to $\mathrm{S}_{3}$ transition: implications for the mechanism of photosynthetic water oxidation. J. Am. Chem. Soc. 123, 7804-7820 (2001).

19. Kulik, L. V., Epel, B., Lubitz, W. \& Messinger, J. Electronic structure of the $\mathrm{Mn}_{4} \mathrm{O}_{\mathrm{x}} \mathrm{Ca}$ cluster in the $\mathrm{S}_{0}$ and $\mathrm{S}_{2}$ states of the oxygen-evolving complex of photosystem II based on pulse ${ }^{55} \mathrm{Mn}$-ENDOR and EPR spectroscopy. J. Am. Chem. Soc. 129, 13421-13435 (2007).

20. Kolling, D. R. J., Cox, N., Ananyev, G. M., Pace, R. J. \& Dismukes, G. C. What are the oxidation states of manganese required to catalyze photosynthetic water oxidation? Biophys. J. 103, 313-322 (2012).

21. Pace, R. J., Jin, L. \& Stranger, R. What spectroscopy reveals concerning the Mn oxidation levels in the oxygen evolving complex of photosystem II: X-ray to near infra-red. Dalt. Trans. 41, 11145-11160 (2012).

22. Rappaport, F., Blanchard-Desce, M. \& Lavergne, J. Kinetics of electron transfer and electrochromic change during the redox transitions of the photosynthetic oxygen evolving complex. Biochim. Biophys. Acta 1184, 178-192 (1994).

23. Koike, H., Hanssum, B., Inoue, Y. \& Renger, G. Temperature dependence of the S-state transitions in a thermophilic cyanobacterium, Synechococcus vulcanus
Copeland measured by absorption changes in the ultraviolet region. Biochim. Biophys. Acta 893, 524-533 (1987).

24. Razeghifard, M. R. \& Pace, R. J. EPR kinetic studies of oxygen release in thylakoids in PSII membranes: a kinetic intermediate in the $S_{3}$ to $S_{0}$ transition. Biochemistry 38, 1252-1257 (1999).

25. Dilbeck, P. L. et al. The D1-D61N mutation in synechocystis sp PCC 6803 allows the observation of $\mathrm{pH}$-sensitive intermediates in the formation and release of $\mathrm{O}_{2}$ from photosystem II. Biochemistry 51, 1079-1091 (2012).

26. Messinger, J., Badger, M. \& Wydrzynski, T. Detection of one slowly exchanging substrate water molecule in the $\mathrm{S}_{3}$ state of photosystem II. Proc. Natl Acad. Sci. USA 92, 3209-3213 (1995).

27. Suzuki, H., Sugiura, M. \& Noguchi, T. Monitoring water reactions during the S-state cycle of the photosynthetic water-oxidizing center: Detection of the DOD bending vibrations by means of Fourier transform infrared spectroscopy. Biochemistry 47, 11024-11030 (2008).

28. Cox, N. \& Messinger, J. Reflections on substrate water and dioxygen formation. Biochim. Biophys. Acta 1827, 1020-1030 (2013).

29. Dau, H. et al. The mechanism of water oxidation: from electrolysis via homogeneous to biological catalysis. ChemCatChem 2, 724-761 (2010).

30. Messinger, J. Evaluation of different mechanistic proposals for water oxidation in photosynthesis on the basis of $\mathrm{Mn}_{4} \mathrm{O}_{\mathrm{x}} \mathrm{Ca}$ structures for the catalytic site and spectroscopic data. Phys. Chem. Chem. Phys. 6, 4764-4771 (2004).

31. Vinyard, D. J., Ananyev, G. M. \& Dismukes, G. C. Photosystem II: the reaction center of oxygenic photosynthesis. Annu. Rev. Biochem. 82, 577-606 (2013).

32. Sproviero, E. M., Gascon, J. A., McEvoy, J. P., Brudvig, G. W. \& Batista, V. S. Quantum mechanics/molecular mechanics study of the catalytic cycle of water splitting in photosystem II. J. Am. Chem. Soc. 130, 3428-3442 (2008).

33. McEvoy, J. P. \& Brudvig, G. W. Water-splitting chemistry of photosystem II. Chem. Rev. 106, 4455-4483 (2006).

34. Taguchi, T. et al. Preparation and properties of a monomeric high-spin MnVoxo complex. J. Am. Chem. Soc. 134, 1996-1999 (2012).

35. Pecoraro, V. L., Baldwin, M. J., Caudle, M. T., Hsieh, W.-Y. \& Law, N. A. A proposal for water oxidation in photosystem II. Pure Appl. Chem. 70, 925-929 (1998).

36. Siegbahn, P. E. M. O-O bond formation in the $\mathrm{S}_{4}$ state of the oxygen-evolving complex in photosystem II. Chem. Eur. J. 12, 9217-9227 (2006).

37. Hillier, W. \& Wydrzynski, T. ${ }^{18} \mathrm{O}$-Water exchange in photosystem II: Substrate binding and intermediates of the water splitting cycle. Coord. Chem. Rev. 252, 306-317 (2008).

38. Petrie, S., Stranger, R. \& Pace, R. J. Hydration preferences for $\mathrm{Mn}_{4} \mathrm{Ca}$ cluster models of photosystem II: Location of potential substrate-water binding sites. Chem. Eur. J. 16, 14026-14042 (2010).

39. Sproviero, E. M. et al. QM/MM computational studies of substrate water binding to the oxygen-evolving centre of photosystem II. Philos. Trans. R. Soc. Lond. B 363, 1149-1156 (2008).

40. Siegbahn, P. E. M. Substrate water exchange for the oxygen evolving complex in PSII in the $\mathrm{S}_{1}, \mathrm{~S}_{2}$, and $\mathrm{S}_{3}$ states. J. Am. Chem. Soc. 135, 9442-9449 (2013).

41. Beckmann, K., Messinger, J., Badger, M. R., Wydrzynski, T. \& Hillier, W. On-line mass spectrometry: membrane inlet sampling. Photosynth. Res. 102, 511-522 (2009).

42. Hillier, W. \& Wydrzynski, T. Substrate water interactions within the photosystem II oxygen evolving complex. Phys. Chem. Chem. Phys. 6, 4882-4889 (2004).

43. Haumann, M. et al. Photosynthetic $\mathrm{O}_{2}$ formation tracked by time-resolved X-ray experiments. Science 310, 1019-1021 (2005).

44. Kern, J. et al. Simultaneous femtosecond X-ray spectroscopy and diffraction of photosystem II at room temperature. Science 340, 491-495 (2013).

45. Ishida, N. et al. Biosynthetic exchange of bromide for chloride and strontium for calcium in the photosystem II oxygen-evolving enzymes. J. Biol. Chem. 283, 13330-13340 (2008).

46. Boussac, A., Ishida, N., Sugiura, M. \& Rappaport, F. Probing the role of chloride in Photosystem II from Thermosynechococcus elongatus by exchanging chloride for iodide. Biochim. Biophys. Acta 1817, 802-810 (2012).

47. Koua, F. H. M., Umena, Y., Kawakami, K. \& Shen, J. R. Structure of Sr-substituted photosystem II at $2.1 \AA$ A resolution and its implications in the mechanism of water oxidation. Proc. Natl Acad. Sci. USA 110, 3889-3894 (2013).

48. Murray, J. W. et al. X-ray crystallography identifies two chloride binding sites in the oxygen evolving centre of Photosystem II. Energy Environ. Sci. 1, 161-166 (2008).

49. Kawakami, K., Umena, Y., Kamiya, N. \& Shen, J.-R. Location of chloride and its possible functions in oxygen-evolving photosystem II revealed by X-ray crystallography. Proc. Natl Acad. Sci. USA 106, 8567-8572 (2009).

50. Pushkar, Y. L., Yano, J., Sauer, K., Boussac, A. \& Yachandra, V. K. Structural changes in the $\mathrm{Mn}_{4} \mathrm{Ca}$ cluster and the mechanism of photosynthetic water splitting. Proc. Natl Acad. Sci. USA 105, 1879-1884 (2008).

51. Hendry, G. \& Wydrzynski, T. ${ }^{18} \mathrm{O}$ isotope exchange measurements reveal that calcium is involved in the binding of one substrate-water molecule to the oxygen-evolving complex in photosystem II. Biochemistry 42, 6209-6217 (2003). 
52. Romain, S., Vigara, L. \& Llobet, A. Oxygen-oxygen bond formation pathways promoted by ruthenium complexes. Acc. Chem. Res. 42, 1944-1953 (2009).

53. Gao, Y., Åkermark, T., Liu, J. H., Sun, L. C. \& Åkermark, B. Nucleophilic attack of hydroxide on a $\mathrm{Mn}^{\mathrm{V}}$ oxo complex: a model of the $\mathrm{O}-\mathrm{O}$ bond formation in the oxygen evolving complex of photosystem II. J. Am. Chem. Soc. 131, 8726-8727 (2009).

54. Vassiliev, S., Zaraiskaya, T. \& Bruce, D. Molecular dynamics simulations reveal highly permeable oxygen exit channels shared with water uptake channels in photosystem II. Biochim. Biophys. Acta 1827, 1148-1155 (2013).

55. Persson, E. \& Halle, B. Nanosecond to microsecond protein dynamics probed by magnetic relaxation dispersion of buried water molecules. J. Am. Chem. Soc. 130, 1774-1787 (2008).

56. Hendry, G. \& Wydrzynski, T. The two substrate water molecules are already bound to the oxygen evolving complex in the $\mathrm{S}_{2}$ state of photosystem II. Biochemistry 41, 13328-13334 (2002).

57. Nilsson, H., Krupnik, T., Kargul, J. \& Messinger, J. Substrate water exchange in photosystem II core complexes of the extremophilic red alga Cyanidioschyzon merolae. Biochim. Biophys. Acta 1837, 1257-1262 (2014).

58. Richens, D. T. Ligand substitution reactions at inorganic centers. Chem. Rev. 105, 1961-2002 (2005).

59. Messinger, J. \& Renger, G. in Processes of Photosynthesis-Part 2: Basic Principles and Apparatus Comprehensive Series in Photochemical and Photobiological Sciences. (ed Renger, G.) 291-349 (The Royal Society of Chemistry, 2008).

60. Meyer, T. J., Huynh, M. H. V. \& Thorp, H. H. The possible role of protoncoupled electron transfer (PCET) in water oxidation by photosystem II. Angew. Chem. Int. Ed. 46, 5284-5304 (2007).

61. Rappaport, F. et al. Probing the coupling between proton and electron transfer in photosystem II core complexes containing a 3-fluorotyrosine. J. Am. Chem. Soc. 131, 4425-4433 (2009).

62. Hays, A.-M. A., Vassiliev, I. R., Golbeck, J. H. \& Debus, R. J. Role of D1-His190 in the proton coupled oxidation of tyrosine $\mathrm{Y}_{\mathrm{Z}}$ in manganese depleted photosystem II. Biochemistry 38, 11851-11865 (1999).

63. Schilstra, M. J., Rappaport, F., Nugent, J. H. A., Barnett, C. J. \& Klug, D. R. Proton/hydrogen transfer affects the S-state dependent microsecond phases of $\mathrm{P}_{680}{ }^{+}$reduction during water splitting. Biochemistry 37, 3974-3981 (1998).

64. Christen, G., Seeliger, A. \& Renger, G. P680 ${ }^{+}$. reduction kinetics and redox transition probability of the water oxidizing complex as a function of $\mathrm{pH}$ and H/D isotope exchange in spinach thylakoids. Biochemistry 38, 6082-6092 (1999).

65. Sjöholm, J., Havelius, K. G. V., Mamedov, F. \& Styring, S. Effects of pH on the $\mathrm{S}_{3}$ state of the oxygen evolving complex in photosystem II probed by EPR split signal induction. Biochemistry 49, 9800-9808 (2010).

66. Navarro, M. P. et al. Ammonia binding to the oxygen-evolving complex of photosystem II identifies the solvent-exchangeable oxygen bridge ( $\mu$-oxo) of the manganese tetramer. Proc. Natl Acad. Sci. USA 110, 15561-15566 (2013).

67. Rapatskiy, L. et al. Detection of the water-binding sites of the oxygen-evolving complex of photosystem II using W-band ${ }^{17} \mathrm{O}$ electron-electron double resonance-detected NMR spectroscopy. J. Am. Chem. Soc. 134, 16619-16634 (2012).

68. Rappaport, F., Ishida, N., Sugiura, M. \& Boussac, A. $\mathrm{Ca}^{2+}$ determines the entropy changes associated with the formation of transition states during water oxidation by photosystem II. Energy Environ. Sci. 4, 2520-2524 (2011).
69. Sugiura, M., Boussac, A., Noguchi, T. \& Rappaport, F. Influence of Histidine198 of the D1 subunit on the properties of the primary electron donor, P680, of photosystem II in Thermosynechococcus elongatus. Biochim. Biophys. Acta 1777, 331-342 (2008).

70. Sugiura, M. \& Inoue, Y. Highly purified thermo-stable oxygen-evolving photosystem II core complex from the thermophilic cyanobacterium Synechococcus elongatus having his-tagged CP43. Plant Cell Physiol. 40, 1219-1231 (1999).

\section{Acknowledgements}

Miwa Sugiura is acknowledged for the gift of the His-tagged strain. We thank Nick Cox and Dimitrios Pantazis for discussions and suggestions regarding the manuscript. Dimitrios Pantazis has provided data for Fig. 1a and Dmitriy Shevela prepared the final versions of all figures. We acknowledge Per Siegbahn, Ron Pace and Jerome Lavergne for ongoing discussions concerning the mechanism of water oxidation, and the Max-Planck Institute for Chemical Energy Conversion for the loan of the isotope ratio mass spectrometer (to J.M).

HN and JM were supported by the Artificial Leaf Project Umeå (K\&A Wallenberg foundation), the Solar Fuels Strong Research Environment Umeå (Umeå University), Vetenskapsrådet and Swedish Energy Agency (Energimyndigheten). AB was supported in part by the French Infrastructure for Integrated Structural Biology (FRISBI) ANR-10INSB-05-01 and by the 'Bioénergie' program from CEA/DSV. FR acknowledges financial support from the CNRS and the 'Initiative d'Excellence' program from the French state (Grant 'DYNAMO', ANR-11-LABX-0011-01).

\section{Author contributions}

The experiment was conceived by F.R., A.B. and J.M. The samples were prepared by A.B and the water-exchange experiments were performed and analysed by H.N. under the supervision of J.M. Proton release measurements were performed by F.R. and A.B. The manuscript was written by F.R., A.B. and J.M. with contributions of H.N.

\section{Additional information}

Supplementary Information accompanies this paper at http://www.nature.com/ naturecommunications

Competing financial interests: The authors declare no competing financial interests.

Reprints and permission information is available online at http://npg.nature.com/ reprintsandpermissions/

How to cite this article: Nilsson, H. et al. Substrate-water exchange in photosystem II is arrested before dioxygen formation. Nat. Commun. 5:4305 doi: 10.1038/ncomms5305 (2014).

cc) (1) $\Theta$ This work is licensed under a Creative Commons AttributionNonCommercial-NoDerivs 4.0 International License. The images or other third party material in this article are included in the article's Creative Commons license, unless indicated otherwise in the credit line; if the material is not included under the Creative Commons license, users will need to obtain permission from the license holder to reproduce the material. To view a copy of this license, visit http:// creativecommons.org/licenses/by-nc-nd/4.0/ 